\section{MERALGIA PARESTHETICA DUE TO FRACTURE OF ANTERIOR SUPERIOR ILIAC SPINE IN AN ADOLESCENT}

To the editor: A 15-year-old boy presented to the emergency department with a sharp pain localized in the right inguinal area associated with tingling on the lateral aspect of his right thigh. The pain started immediately after he kicked a ball during a football game. At that time, he was unable to continue his activity. Palpation produced localized tenderness at the right anterior superior iliac spine (ASIS). The pain was aggravated by hip movements, especially with internal rotation. Neurological examination revealed paresthesia in the lateral region of the thigh. Anteroposterior and iliac view radiographs of the pelvis showed an avulsion fracture of the ASIS. Physical examination and radiological findings led to a diagnosis of meralgia paresthetica (MP) due to an ASIS avulsion fracture. The patient was managed with a nonsteroidal antiinflammatory drug and limited weight bearing with crutches. Four weeks after the initial injury, he was able to walk without crutches and with minimal pain. However, parethesia on the lateral aspect of his thigh persisted. At the final follow-up, 3 months after the initial injury, the patient had no pain and no restriction of hip movements. The paresthesia had resolved completely and he was able to return to his normal level of sports activity.

Meralgia paresthetica is an entrapment neuropathy of the lateral femoral cutaneous nerve that is characterized by pain and paresthesia on the anterolateral aspect of the thigh. Several etiologies have been described and several risk factors have been attributed in the pathogenesis of this condition. ${ }^{1}$ Although up to 80 different causes have been reported in the literature, an ASIS avulsion fracture is an extremely rare cause of MP in the relevant literature. ${ }^{1-3}$

The ASIS is the origin of the sartorius anteriorly and the tensor fascia lata more laterally and posteriorly. Sudden forceful concentric contractions of these muscles may result in an avulsion fracture of the ASIS in adolesecents because the musculotendinous unit is stronger than the apophyseal cartilage. ${ }^{4}$ The lateral femoral cutaneous nerve is susceptible to injury because it is anatomically close to the ASIS. A study that investigated the anatomy of the lateral femoral cutaneous nerve in 52 cadavers found it was ensheathed in the tendinous origin of the sartorius muscle. ${ }^{5}$ The probable mechanism of injury in our case was neurapraxia of the lateral femoral cutaneous nerve due to traction of the nerve with the anterior displacement of the sartorius origin, or compression of the nerve by the fracture hematoma. Resolution of the neurologic symptoms within 3 months supports this hypothesis.

Meralgia paresthetica may be a presenting symptom of an ASIS avulsion fracture. Conservative managment should be the choice of initial treatment.

\section{Ozkan Kose, MD}

Consultant Surgeon, Orthopaedics and Traumatology Department, Diyarbakir State Hospital,

Diyarbakir, Turkey

\section{Selahattin Ozyurek, MD}

Consultant Surgeon, Orthopaedics and Traumatology Department, Izmir Military Hospital, Izmir, Turkey

\section{References}

1. Harney D, Patijn J. Meralgia paresthetica: diagnosis and management strategies. Pain Med 2007;8:669-77.
2. Buch KA, Campbell J. Acute onset meralgia paraesthetica after fracture of the anterior superior iliac spine. Injury 1993;24:569-70.

3. Thanikachalam M, Petros JG, O'Donnell S. Avulsion fracture of the anterior superior iliac spine presenting as acute-onset meralgia paresthetica. Ann Emerg Med 1995;26:515-7.

4. White KK, Williams SK, Mubarak SJ. Definition of two types of anterior superior iliac spine avulsion fractures. 7 Pediatr Orthop 2002;22:578-82.

5. Aszmann OC, Dellon ES, Dellon AL. Anatomical course of the lateral femoral cutaneous nerve and its susceptibility to compression and injury. Plast Reconstr Surg 1997;100:600-4.

\section{DENTAL BRACES AS A CAUSE OF AIRWAY OBSTRUCTION}

To the editor: A 15-year old boy was involved in a high-speed single-vehicle crash in which he was the passenger and required extrication with the jaws of life. He had obvious severe head injuries, including brain protrusion. Prehospital intubation was unsuccessful because of reported "clenching."

On arrival at the emergency department, the patient's oxygen saturation was recorded at $76 \%$, with an obvious facial smash. Attempts to open his mouth failed because of apparent clenching of his teeth. Nasopharyngeal airway was considered to be relatively contraindicated because of the facial injuries. Vigorous 2-handed bag mask ventilation with in line stabilization improved his oxygen saturation to $82 \%$, with significant high pressure air leak around the mask. Closer examination revealed that his upper gums were visible between his lips, but not the occlusive area of the incisors. Our initial impression was that he had had his jaw wired shut. Further examination revealed that the mucosa of his lower lip had become closely and tightly fastened to the 
braces on his upper teeth, effectively sealing his mouth shut (including the interdental spaces). We were able to free up the lip and open the mouth by pulling the lip cephalad and "popping" the mucosa off each brace fastener by sliding an index finger between the lower teeth and inner lip. An uneventful lightwand intubation followed, with restoration of $100 \%$ oxygen saturation.

To our knowledge this occur- rence, which might easily have led to the patient's death in the field, has not been described before.

We presume that, in spite of his facial injuries, his nostrils had enough patency to allow enough oxygenation to sustain him during transport and initial ED assessment. He did, however, experience a prolonged period of hypoxia. Unfortunately, his injuries subsequently proved to be fatal.
Samuel G. Campbell, MB BCh, CCFP(EM), Dip PEC (SA), CHE

Associate Professor of Emergency Medicine, Dalhousie University

Chief, Department of Emergency Medicine, Queen Elizabeth II Health Sciences Centre, Halifax, NS

Glen Etsell, CCP

Department of Emergency Medicine, Queen Elizabeth II Health Sciences Centre, Halifax, NS

\section{ARE YOU READY FOR AN OUTBREAK?}

UP TO 6 STUDY HOURS/CREDITS

MAINPRO M1, MAINCERT SECTION 1, FMOQ CATEGORY 1

Infectious Disease Outbreaks: Tools and strategies for front-line clinicians describes how the health care and public health systems need to work together to control infectious disease outbreaks - from mumps to a pandemic. Protect yourself, your family and your community.

\section{NEW ONLINE COURSE}

Sign-up now at: www.publichealth.gc.ca/outbreaks-course Endorsed by the provincial/territorial Ministries of Health

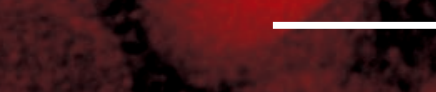

